\title{
A Technique for Shell Compression Measurements of Laser Fusion Targets by Neutron Activation of a Rubidium Tracer
}

\author{
Stephen M. Lane and Michael B. Nelson
}

This paper was prepared for submittal to The Eigth Topical Conference on High-Temperature Plasma Diagnostics

May 6-10, 1990, Hyannis, Mass.

\section{December 7, 1990}

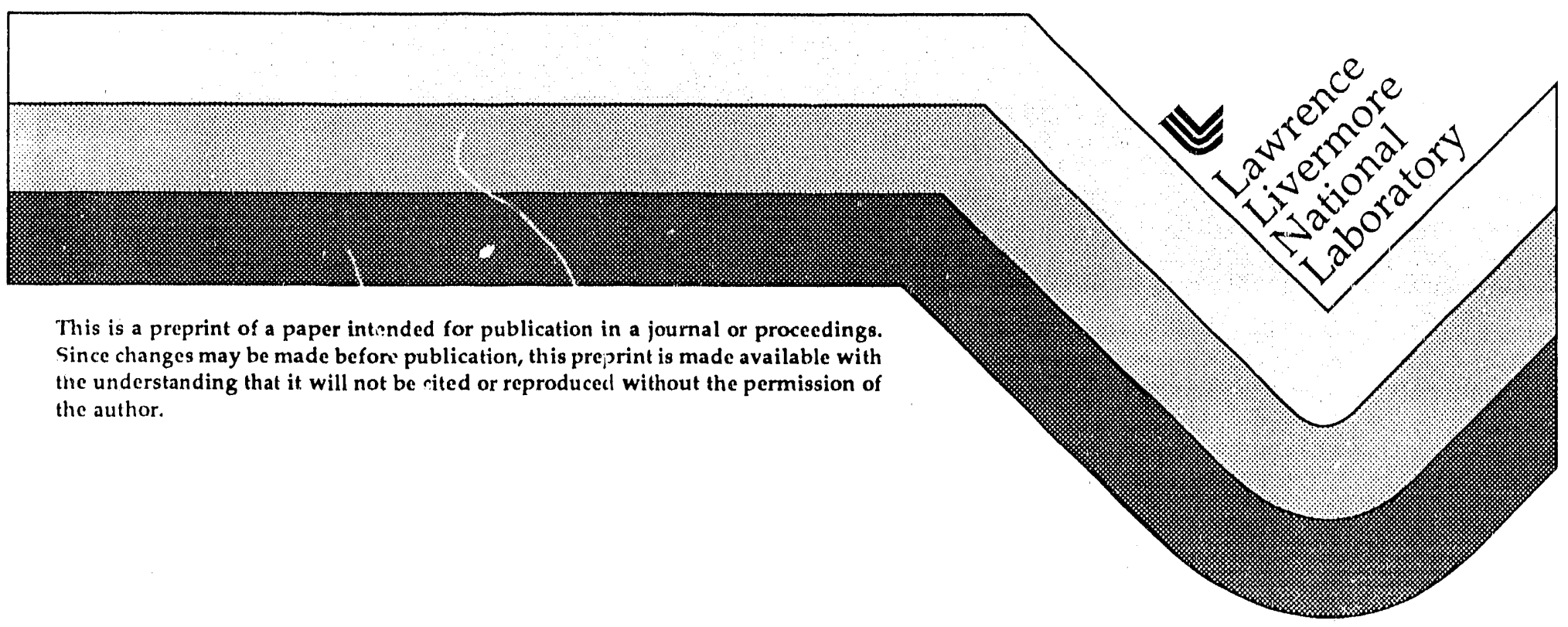

\section{MASTER}




\section{MSCOAMITK}

This document was prepared as an account of work sponsored by an agency of the I nited States Ciovernment. Neither the I nited States Ciovernment nor the Iniversity of California nor any of their employees, makes any warraney, express or implied, or assumes any lepal liability or responsibility for the $\mathrm{HC}$ curacy, completeness, or usefulness of any information, apparatus, product, or process disclosed, or represents that its use nould not infringe privately on ned rights. Reference herein to any specific commercial products, process, or service by trade name, trademark, manufacturer, or otherwise, does mot necessarily constitute or imply its endorsement, recommendation, or favoring by the l'nited States Covernment or the l'niversity of California. The tiens and opinions of authors expressed herein do not necessarily state or reflect those of the I nited states Covernment thereof, and shall not be used for adicertising or product endorsement purposes. 


\title{
A technique for shell compression measurements of laser fusion targets by neutron activation of a rubidium tracer
}

\author{
Stephen M. Lane and Michael B. Nelson \\ Lawrence Livermore National Laboratory, Livermore, California 94550
}

\begin{abstract}
At the Nova Laser, the activation of a rubidium tracer incorporated in the shell of ICF targets has become a standard diagnostic technique for measuring the compressed shell areal density $\langle\rho \Delta R>$. The isotope ${ }^{85} \mathrm{Rb}$ is activated by $14 \mathrm{MeV}$ implosion neutrons to produce the isomer ${ }^{84 \mathrm{~m}} \mathrm{Rb}\left(\mathrm{t}_{1 / 2}=\right.$ $20.5 \mathrm{~min})$ which is used to determine the shell $\left\langle\rho \Delta R>\right.$ while the radioactive isotope ${ }^{86} \mathrm{Rb}\left(\mathrm{t}_{1 / 2}=\right.$ $18.8 \mathrm{~d}$ ) is used to determine the fraction of target debris collected as well as to assay the amount of rubidium in the target. The ${ }^{85} \mathrm{Rb}(\mathrm{n}, 2 \mathrm{n})^{84 \mathrm{~m} R \mathrm{R}}$ cross-section at $14.1 \mathrm{MeV}$ was measured $(\sigma=0.514 \pm 0.080 \mathrm{~b})$. Details of the detector system and experimental technique are given.
\end{abstract}




\section{I.INTRODUCTION}

The measurement of the neutron averaged areal density $\langle\rho \Delta R>$ of the compressed pusher of an ICF target by neutron activation has become a well established technique. ${ }^{1-5}$ Its implementation involves the activation of one or more elemental constituents of the pusher by $14 \mathrm{MeV}$ neutrons produced in an implosion. Pusher debris containing these activated atoms is then collected on metal foils placed near the target. These foils are transferred to a radiation detector that measures the individual activity levels. The $\langle\rho \Delta R>$ is determined from the expression

$$
<\rho \Delta R>=\frac{C A}{\sigma Y N_{\mathrm{o}} f \eta_{C} \eta_{D} e^{-\lambda t_{d}}\left(1-e^{-\lambda t_{c}}\right)}
$$

where $C$ is the number of detected counts, $A$ is the average atomic weight of a pusher atom, $\sigma$ is the activation cross-section, $Y$ is the neutron yield, $N_{\mathrm{o}}$ is Avogadro's number, $f$ is the fraction of atoms of the isotope to be activated compared to the total number of pusher atoms, $\eta_{C}$ is the fraction of activated atoms collected, $\eta_{D}$ is the detection efficiency, $\lambda$ is the decay constant, $t_{d}$ is the time to load the detector, and $t_{c}$ is the counting time. The angle brackets indicate the measured value is an average weighted by the neutron production rate as well as an average over all neutron paths through the shell.

Previous $\left\langle\rho \Delta R>\right.$ activation measurements have mostly used the ${ }^{28} \mathrm{Si}(\mathrm{n}, \mathrm{p}){ }^{28} \mathrm{Al}$ reaction on microshell targets made of either glass ${ }^{1-4}$ or silicon-doped plastic. ${ }^{5}$ The principal deficiency of this technique is that the fraction of $\mathrm{Al}$ collected $\left(\eta_{C}\right)$ cannot be measured directly. One must therefore 
either measure the $\mathrm{Al}$ collection fraction by comparison with some other method of determining $<\rho \Delta R>$ and then assume $\eta_{C}$ is constant from shot-to-shot, or, as is more commonly done, the $\mathrm{Al}$ collection fraction is inferred by assuming that it is equal to the measure collection fraction of ${ }^{24} \mathrm{Na}$, a common radioactive tracer in irradiated glass shells. Although under some conditions these assumptions are reasonable, at Nova, under certain conditions, the amount of Na collected varies from shot-to-shot by as much as a factor of 6 and, furthermore, the $\mathrm{Al}$ (inferred from $\mathrm{Rb}<\rho \Delta R>$ ) and $\mathrm{Na}$ collection fractions can differ from each other by as much as a factor of 2 .

An extension of this activation method that does not suffer from these collection problems uses natural rubidium as the tracer. Both natural isotopes of $R b$ undergo $(n, 2 n)$ reactions with 14.1 $\mathrm{MeV}$ fusion neutrons resulting in the activation products $84,84 \mathrm{~m}, 86,86 \mathrm{~m} R \mathrm{~b}$. The isomers, $84 \mathrm{mRb}$ $\left(t_{1 / 2}=20.5 \mathrm{~min}\right)$ and ${ }^{86 \mathrm{~m} R b}\left(t_{1 / 2}=1.02 \mathrm{~min}\right)$, have half-lives short enough to allow reasonable count rates for making the shell $<\rho \Delta R>$ measurement. By irradiating the target with reactor produced thermal neutrons prior to the implosion experiment, the radioactive tracer ${ }^{86} \mathrm{Rb}\left(\mathrm{t}_{1 / 2}=\right.$ $18.8 \mathrm{~d}$ ) is formed throughout the shell. Comparing the ${ }^{86} \mathrm{Rb}$ activity in the target before the implosion to the activity on the collector foils after the implosion gives the fraction of rubidium that was recovered. Thus the same element is used for both the $\langle\rho \Delta R>$ measurement as well as the collection fraction determination. As a further benefit, the ${ }^{86} \mathrm{Rb}$ shell activity can be compared to that of a $\mathrm{RbCl}$ flux monitor to accurately assay the $\mathrm{Rb}$ content in the shell.

\section{DECAY SCHEME AND CROSS-SECTION FOR $84 \mathrm{mRb}$}

The most probable reactions (excluding elastic and inelastic scattering) of $14 \mathrm{MeV}$ neutrons with $R b$ are $(n, 2 n)$ reactions. Relevant properties of the $(n, 2 n)$ reaction products from Refs. 6- 
8 are listed in Table 1. The decay scheme for $84 \mathrm{mRb}$, the reaction product we find most convenient to use, shows the three gamma rays emitted by the decay of the isomer (Fig. 1). Because internal conversion competes with gamma emission there are 6 sepirate decay modes as listed with their relative probabilities in Table 2.

There is a large variation among the measurements of the $14.1 \mathrm{MeV}{ }^{85} \mathrm{Rb}(\mathrm{n}, 2 \mathrm{n})^{84 \mathrm{~m} R \mathrm{~b}}$ cross-section. ${ }^{9}$ We remeasured it using our neutron generator facility which produces a well characterized source of $14 \mathrm{MeV}$ neutrons by directing a $200 \mathrm{keV}$ deuteron beam onto a tritiated Ti-on-Cu target. The number of DT neutrons produced was monitored using an absolutely calibrated silicon charged-particle detector that counts the DT alpha particles emitted from the accelerator target. $\mathrm{RbCl}$ samples $(0.5 \mathrm{~g})$ were irradiated with a flux of $10^{5} \mathrm{n} / \mathrm{cm}^{2}-\mathrm{s}$ for 20 minutes at positions $4-8 \mathrm{~cm}$ from the neutron source $\mathrm{cnd}$ at angles of $0,30,45,75$, and 90 degrees to the incident beam direction. Small corrections were made for the angular spread of neutrons across the sample, neutron scattering in the tritium target and in the $\mathrm{RbCl}$ sample, and

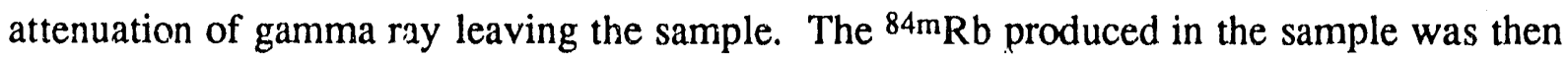
counted in the absolutely calibrated gamma detector described in the next section. The value of our measured cross-section was $0.514 \pm 0.080 \mathrm{~b}$ which is close to the average of previous measurements compiled in Ref. 9.

\section{GAMMA-RAY DETECTION}

A pair of coaxial high-purity intrinsic-germanium well detectors are used to count the gamma rays emitted by the collected rubidium. These detectors have an active volume of $145 \mathrm{~cm}^{3}$ 
each and are operated in a face-to-face geometry (Fig. 2) with the collector foils wound onto a lucite spindle and placed entirely inside the $1.5 \mathrm{~cm}$ diameter, $4 \mathrm{~cm}$ deep wells, thus providing nearly $4 \pi$ detection solid angle. Resolution in the 100 to $500 \mathrm{keV}$ energy range is approximately $2.2 \mathrm{keV}$ FWHM. The detectors are operated independently, but with the gains matched so that the 4096 channel pulse height spectra from the two detectors can be summed for analysis after the experiment. A typical summed gamma spectrum is shown in Fig. 3.

When the $248 \mathrm{keV}$ and $216 \mathrm{keV}$ gamma rays are emitted in cascade, they cannot be resolved temporally and therefore produce summing effects which prevent the absolute detection efficiency from being determined in the usual way which is to use calibrated sources that produce photopeaks in the energy range of interest. Instead, we developed a 3-step calibration procedure. First a ${ }^{152} \mathrm{Eu}$ NBS standard source $(1 \mu \mathrm{Ci})$ was used to calibrate each detector at a position $20 \mathrm{~cm}$ away from their front faces in order to remove the effects of summing. The next step was to

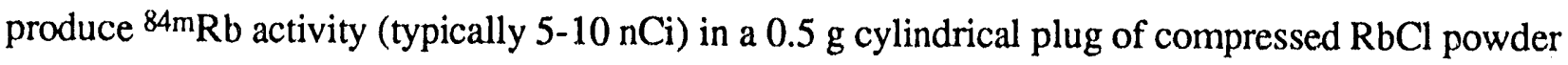
using our $14 \mathrm{MeV}$ neutron generator facility. This sample was then counted in the $20 \mathrm{~cm}$ position to determine its absolute activity (by comparison to the Eu-152 source). The final step was to count the sample at various positions in the detectors. The efficiency for counting ${ }^{84 \mathrm{~m} R \mathrm{~b}}$ at these positions for the three photopeaks was then determined from the peak area divided by the source strength as shown in Fig. 3. Accurate peak areas were obtained for all spectra using the peak fitting code MICROSAMPO ${ }^{10,11}$ run on an IBM-AT personal computer.

\section{IV.RUBIDIUM ASSAY}


To accurately estimate $\langle\rho \Delta R>$, the initial amount and distribution of $\mathrm{Rb}$ in the shell must be known. The distribution of $\mathrm{Rb}$ in glass shells is assumed to be uniform. This assumption is consistent with elemental analyses using characteristic $\mathrm{x}$ rays produced by a tightly focussed electron micrograph beam to interrogate different locations on the exposed wall of a hemispherical shell.

The absolute amount of $\mathrm{Rb}$ is determined by comparing the ${ }^{86} \mathrm{Rb}$ activity in a shell to the ${ }^{86} \mathrm{Rb}$ activity in a $\mathrm{RbCl}$ flux monitor that was irradiated in close proximity to the shell. This is accomplished in the following way: Four target shells are irradiated in a reactor-grade graphite holder for approximately 4 hours in a thermal neutron flux of $9 \times 10^{13} \mathrm{n} / \mathrm{cm}^{2}$-s at the Los Alamos Omega West Reactor. Each holder also contains $41.5 \mathrm{~mm}$ x $1.5 \mathrm{~mm}$ hollow cylindrical flux monitors made of Epon 826 epoxy and Versamid 140 catalyst. (Irradiated empty epoxy cylinders produced insignificant amounts of radioactivity and showed no evidence of contamination from trace amounts of $\mathrm{Rb}$ in the epoxy.) Before sealing, each cylinder is filled with $1 / 2$ microliter of a dilute (50:1) aqueous $\mathrm{RbCl}$ solution which is evaporated to dryness. This technique produces nearly identical $( \pm 2 \%)$ flux monitors containing an accurately known quantity of rubidium $(7.1 \mu \mathrm{g})$ that is comparable to the amount contained in the target and consequently produces a level of activity nearly the same as the target thus allowing the two to be counted in the same physical location in the detector. We find, for instance, that in microshells used for direct-drive implosions $\mathrm{s}^{12}, 1 \%$ of the atoms in the shell are $\mathrm{Rb}$ atoms.

\section{SHELL $\langle\rho \Delta R>$ MEASUREMENTS}


The debris collector is $25 \mu \mathrm{m}$ thick titanium foil formed into a cone $(4 \mathrm{~cm}$ dia. $\mathrm{x} 8 \mathrm{~cm}$ length) and is placed $5 \mathrm{~cm}$ from the target where typically $2 \%$ to $6 \%$ of the rubidium is collected. The foil is recovered from the target chamber, transferred to a counting lab, and loaded into the detector assembly. Transfer and loading takes 1-2 minutes. The counting data are collected from each detector in 10 consecutive 1 -minute 4096 channel spectra followed by 1010 -minute spectra to accomnodate the half-lives of the various activities contained in the target debris. (Typically the following activities can be observed following a direct-drive glass implosion: ${ }^{84 \mathrm{mRb}}(2,0.5 \mathrm{~min})$, ${ }^{86 \mathrm{mRb}}(1.02 \mathrm{~min}),{ }^{86} \mathrm{Rb}(18.8 \mathrm{~d}),{ }^{28} \mathrm{Al}(2.24 \mathrm{~min}),{ }^{29} \mathrm{Al}(6.6 \mathrm{~min}),{ }^{24} \mathrm{Na}(15.02 \mathrm{~h})$, and ${ }^{42} \mathrm{~K}$ $(12.36 \mathrm{~h})$.$) The collector foil is then divided into sections (usually 5) which are counted$ individually using ${ }^{86} \mathrm{Rb}$ to determine the fraction of $\mathrm{Rb}$ collected $\eta_{D}$ as well as the distribution of debris on the foil. This distribution is then used along with the position-dependent detection efficiency (Fig. 3) to calculate an average detection efficiency $\eta_{C}$. Finally, the total $84 \mathrm{mRb}$ counts $C$ in a 40 minute period starting 10 minutes after the shot (to allow time for background from ${ }^{28} \mathrm{Al}$ to decay) is used to compute the shell $\langle\rho \Delta R>$ value using Eq. 1. The natural background $(\sim 1$ $\mathrm{cpm}$ ) is subtracted from the total counts as is a comparable contribution due to Compton events from ${ }^{86} \mathrm{Rb}$ and ${ }^{24} \mathrm{Na}$ garnma rays. The $Y<\rho \Delta R>\eta_{C}$ product required to produce a statistically significant number of counts (about 30 ) is approximately $5 \times 10^{8}$.

\section{VI.CONCLUSION}

The activation of natural rubidium has become a standard implosion diagnostic technique at the Nova Laser Facility for measuring the compressed shell $\langle\rho \Delta R>$. It has supplanted the silicon 
activation technique because of the advantages of a direct collection fraction measurement and the accurate assay of $\mathrm{Rb}$ content of individual shells. The disadvantages are that it is less sensitive as than the $\mathrm{Si}$ technique, it demands that a high- $\mathrm{Z}$ material be placed in the shell which can be undesirable from a target design standpoint, and it requires multi-hour irradiations in a reactor which may damage shells made of plastic.

\section{ACKNOWLEDGEMENTS}

The authors wish to acknowledge the support of the Target Fabrication Group, the Nova Laser Operations Crew, and especially E.M. Campbell, J. Mauger, W. Hatcher, C. Bennett, G. Mant, and E. Lilley of LLNL, as well as M. Bunker, I. Ramsey, and the Omega West Reactor Crew at LANL. This work was performed under the auspices of the U.S. DOE by the Lawrence Livermore National Laboratory under contract No. W-7405-ENG-48. 


\section{REFERENCES}

${ }^{1}$ E.M. Campbell, W.M. Ploeger, P.H. Lee, and S.M. Lane, Appl. Phys. Lett. 36, 965 (1980)

${ }^{2}$ E.M. Campbell, H.G. Hicks, W.C. Mead, L.M. Coleman, C.W. Hatcher, J.H. Dellis, M.J.

Boyle, J.T. Larsen, and S.M. Lane, J. Appl. Phys. 51, 6065 (1980)

${ }^{3}$ S.M. Lane, E.M. Campbell, and C. Bennett, Appl. Phys. Lett. 37, 965 (1980)

${ }^{4}$ F.J. Marshall, S.A. Letzring, C.P. Verdon, S. Skupsky, R.L. Keck, J.P. Knauer, R.L.

Kremens, D.K. Bradley, T. Kessler, J. Delettrez, H. Kim, J.M. S

Phys. Rev. A 40, 2547 (1989)

${ }^{5}$ H. Nakaishi, N. Miyanaga, Y. Setsuhara, H. Azechi, M. Takagi, M. Saito, M. Yamanaka, T.

Yamanaka, S. Nakai, K. Kobayashi, and I. Kimura, Appl. Phys. Lett. 55, 2072 (1989)

${ }^{6}$ C. M. Lederer and V. S. Shirley, Table of Isotopes, Seventh Edition, John Wiley and Sons, Inc., New York, 1978

${ }^{7}$ E. Browne and R. B. Firestone, Table of Radioactive Isotopes, John Wiley and Sons, Inc., New York, 1986

${ }^{8}$ H.W. Muller and J.W. Tepel, Nuc. Data. Sheets 27, 339 (1979)

${ }^{9}$ V. McLane, C.L. Dunford, and P.F. Rose, Neutron Cross Sections, Vol. 2, Academic Press, San Diego, 1988

${ }^{10}$ MICROSAMPO purchased from Logion Oy, Lutherinkatu 2 B 18, 00100 Helsinki, Finland

${ }^{11}$ J.T. Routti and S.G. Prussin, Nucl. instr. Meth. 72, 125 (1969)

${ }^{12}$ Microshell targets were obtained from KMS Fusion, Inc., P.O. Box 1569 Ann Arbor, Ml 48106 
Table 1. $14 \mathrm{MeV}$ Neutron Activation Characteristics of Rubidium

\begin{tabular}{|c|c|c|c|c|}
\hline & \multicolumn{2}{|c|}{${ }^{85} \mathrm{Rb}$} & \multicolumn{2}{|c|}{${ }^{87} \mathrm{Rb}$} \\
\hline Natural Abundance (\%) & \multicolumn{2}{|c|}{72.17} & \multicolumn{2}{|c|}{27.83} \\
\hline Reaction & \multicolumn{2}{|c|}{$(n, 2 n)$} & \multicolumn{2}{|c|}{$(n, 2 n)$} \\
\hline Reaction Product & ${ }^{84} \mathrm{Rb}$ & ${ }^{84} \mathrm{~m}_{\mathrm{Rb}}$ & ${ }^{86} \mathrm{Rb}$ & ${ }^{86} \mathrm{~m} R \mathrm{~b}$ \\
\hline Threshold (MeV) & 10.49 & 10.95 & 10.48 & 11.03 \\
\hline Cross-Section (mb) & 1130 & 450 & 620 & 520 \\
\hline Half-life & $32.77 \mathrm{~d}$ & $20.5 \mathrm{~min}$ & $18.82 \mathrm{~d}$ & $1.02 \mathrm{~min}$ \\
\hline Gamma-1 Energy (keV) & 882 & 216 & 1077 & 556 \\
\hline Gamma-1 Intensity (\%) & 74 & 34 & 8.79 & 98.2 \\
\hline Gamma -2Energy (keV) & & 248 & & \\
\hline Gamma-2 Intensity (\%) & & 63 & & \\
\hline Gamma -3 Energy (keV) & & 465 & & \\
\hline Gamma -3 Intensity (\%) & & 31 & & \\
\hline
\end{tabular}

Table 2. Decay modes of ${ }^{84 \mathrm{~m} R b}$ derived from $\gamma$ intensities and IC coefficients in Ref. 8.

\begin{tabular}{ccccc}
\hline Deciay Mode & $465 \rightarrow$ Grnd & $465 \rightarrow 248$ & $248 \rightarrow$ Grnd & Rel. Probability \\
\hline 1 & $\gamma$ & & & 0.310 \\
2 & IC & $\gamma$ & $\gamma$ & 0.050 \\
3 & & $\gamma$ & IC & 0.332 \\
4 & & IC & $\gamma$ & 0.008 \\
5 & IC & IC & 0.293 \\
6 & & & 0.007 \\
\hline
\end{tabular}

$\gamma=$ gamma emission; $\mathrm{IC}=$ internal conversion 

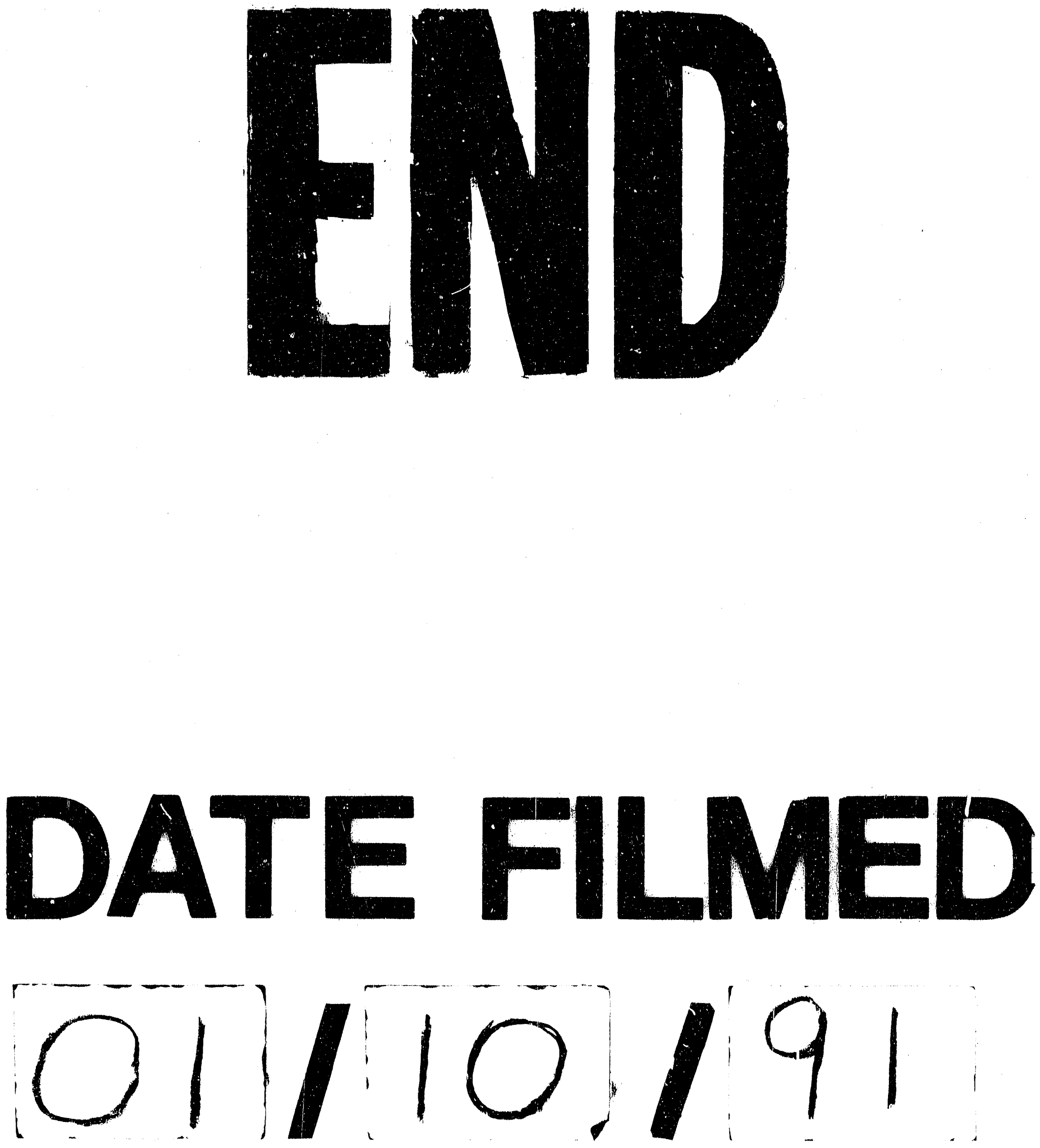
